\title{
RESPONSABILIDAD EMPRESARIAL POR RIESGOS AMBIENTALES EN ESPAÑA: IMPLICACIONES JURÍDICAS Y ESTRATÉGICAS.
}

\author{
Pilar Dopazio Fraguío*
}

\begin{abstract}
Sumario: 1.-Marco jurídico y estratégico de la responsabilidad empresarial por riesgos ambientales. Presentación y motivación de la temática. 2.-Tratamiento legal de la responsabilidad ambiental empresarial en la Ley 26/2007 (LRMA) y su desarrollo reglamentario. 3.- Consideración del riesgo ambiental a efectos de atribución de la responsabilidad en elámbito dela nueva gobemanza corporativa. 4.-Fómula jurídica adoptada por el legislador: Tipos de responsabilidad en la LRMA. 5.- Análisis de riesgos ambientales. 6.- Garantías financieras obligatorias. 7.- Causas de exoneración de la responsabilidad. 8.-Medidas preventivas, medidas de evitación y medidas de reparación de daños ambientales. 9.-Conclusión. Consideraciones parauna estrategia empresarial responsable y sostenible.
\end{abstract}

- Resumen: Este trabajo parte de un análisis del derecho positivo español; en concreto, se centra en el análisis del marco normativo instaurado por la LRMA, para proseguir con la consideración de los principales aspectos técnicos y jurídicos determinantes del régimen vigente en materia de responsabilidad ambiental empresarial. Significar, con carácter previo, que de forma especial es objeto de análisis el tratamiento de la responsabilidad objetiva con referencia al desarrollo de una actividad empresarial o profesional, capacitada para generar impacto ambiental y, en consecuencia, apreciando el riesgo ambiental de la misma.

- Palabras-clave: responsabilidad empresarial; riesgos ambientales; marco normativo; derecho positivo español.

Abstract: This paper is an analysis of Spanish positive law, in particular, focuses on the analysis of the regulatory framework established by LRMA, for further consideration of the main determinants of technical and legal aspects of the current regime on environmental liability companies. It is especially considered the treatment of strict liability with respect to the development of a business or professional capacity to generate environmental impacts and, therefore, assess the environmental risks.

- Keywords: corporate responsibility; environmental risks; regulatory framework; Spanish positive law.

\section{1.- Marco jurídico y estratégico de la responsabilidad empresarial por riesgos ambientales. Presentación y motivación de la temática.}

En el ordenamiento jurídico español, la vigente Ley 26/2007 de Responsabilidad Medioambiental (LRMA) junto con su desarrollo reglamentario ${ }^{1}$

\footnotetext{
* Doctor en Derecho. Abogado. Profesor asociado de la Universidad Carlos III de Madrid España ${ }^{1}$ LRMA: Ley 26/2007, de 23 de octubre, de Responsabilidad Medioambiental (BOE núm. 255, de 24 de octubre de 2007) y Real Decreto 2090/2008, de 22 de diciembre, por el que se aprueba el Reglamento de desarrollo parcial de la LRMA (BOE núm. 308, de 23 de diciembre de 2008). A través de la citada LRMA, conforme advierte su Preámbulo, se realiza la trasposición de la Directiva 2004/35/CE del Parlamento Europeo y del Consejo, de 21 de abril de 2004, sobre Responsabilidad medioambiental en relación con la prevención y reparación de daños medioambientales, con la finalidad de fijar un modelo jurídico eficaz y armonizado que supere las fórmulas jurídicas tradicionalmente aplicadas en esta materia.
} 
constituyen una relevante aportación en el ámbito de los instrumentos de tutela ambiental y, de forma específica, en materia de responsabilidad civil de las empresas.

La citada Ley, como novedad, propugna un sistema de responsabilidad para la prevención y reparación de los daños ambientales; al mismo tiempo que considera desde una perspectiva jurídica el valor económico y financiero del riesgo ambiental, prescribiendo su adecuado tratamiento e internalización en el propio modelo de gestión de la actividad económica, empresarial o profesional que se desarrolle.

En este sentido, conviene analizar la fórmula legal adoptada, destacando su interés a efectos de estimar las implicaciones que conlleva. Entre otras, la necesidad de diseñar y adoptar una planificación empresarial estratégica adecuada, que facilite el cumplimiento de las obligaciones jurídicas prescritas y de los propios compromisos voluntariamente asumidos por la organización o empresa responsable (operador) en cada caso. Así, conforme a un concepto avanzado de Responsabilidad Social Corporativa o Empresarial (RSC o RSE) ${ }^{2}$, dicha planificación estratégica deberá ser acorde con un modelo de empresa responsable y sostenible, permitiendo de este modo asegurar el cumplimiento de los requisitos legales y, de forma paralela, garantizar su crecimiento y competitividad.

Es un hecho cierto, guiado por la lógica de los acontecimientos económicos y financieros sucedidos en los últimos años, que en la práctica empresarial actual se observa como gran número de organizaciones -en especial, las medianas y pequeñas empresas (pymes y micropymes)- se enfrentan al reto

\footnotetext{
${ }^{2}$ Precisar en este punto, que conforme a la interpretación actual del concepto de "responsabilidad empresarial por riesgos ambientales" -al igual que otro tipo de riesgos estratégicos- ésta se ha de considerar directamente vinculada a la concepción de los modelos integrados de gobierno corporativo y responsabilidad social-ambiental, configurados de forma unívoca como sistemas estratégicos de gestión empresarial proactiva y eficiente. Así mismo, con carácter previo, señalar que los vocablos de Responsabilidad Corporativa o Empresarial no hacen referencia sólo a las sociedades cotizadas, sino que también es necesario resaltar su interés y viabilidad para la las sociedades no cotizadas. En el mismo sentido, considerar su extensión a las pequeñas y medianas empresas (pymes) y micropymes; y, en general, a todo tipo de organizaciones -privadas o públicas- que pretendan como objetivo la sostenibilidad, cualquiera que fuera su forma jurídica, dimensión o sector de actividad. Por tanto, en un sentido amplio y conforme a su concepción actual los conceptos RSC y RSE pueden utilizarse como sinónimos. Si bien, en puridad, recordar la precisión doctrinal ofrecida por SALAS FUMÁS, V., exponiendo con rigor que el término "corporativo" hace la referencia a la gran empresa sociedad anónima cotizada (conforme a la concepto jurídico anglosajón corporation) en la que adquiere relevancia un posible conflicto de intereses entre accionistas -mayoritarios/minoritarios- y directivos. Por el contrario, señala el autor, "la responsabilidad es un concepto que trasciende a la forma jurídica de la empresa". (op. cit., p. 10, nota n 7, SALAS FUMÁS, V.: "¿Sustituye la responsabilidad social al buen gobierno de la empresa?", en el núm. monográfico titulado "Empresa Sostenible", Economistas 106/ 2005, Colegiode Economistas de Madrid, pp.4-11.
} 
del cambio socio-cultural y del modelo económico pronosticado. En consecuencia, en el momento presente, todavía algunas empresas precisan una "renovación" -en ciertos casos radical- de sus políticas y sistemas de gestión, para adecuarlos al marco legal vigente y proyectado; lo que supone un requerimiento fundamental para la competitividad de las mismas. Este necesario proceso de "renovación" (adaptación a los nuevos planteamientos) implica, en muchos casos, un coste, que deberá ser convenientemente previsto, planificando su cobertura y amortización, convirtiéndolo en una inversión rentable para la propia empresa y su entorno, con la implicación de todos los grupos de interés. En este aspecto, la legítima pretensión de generar valor y rentabilidad debe ser interpretada conforme a la contribución económica, social y ambiental aportada por cada empresa. Sólo de esta forma, apreciando este enfoque, podrá estimarse en su justa medida el concepto y las implicaciones de la responsabilidad empresarial ambiental como "estrategia para la sostenibilidad y la competitividad".

Precisamente, la consideración de la citada premisa se configura como un argumento válido y motivador del presente estudio. Siendo, al mismo tiempo, la base principal de una pretensión: propiciar un nuevo enfoque estratégico empresarial para aportar compromiso, confianza y valor (individual y colectivo), tanto para la propia empresa como para el mercado y la sociedad.

De este modo, este trabajo parte de un análisis del derecho positivo español; en concreto, se centra en el análisis del marco normativo instaurado por la LRMA, para proseguir con la consideración de los principales aspectos técnicos y jurídicos determinantes del régimen vigente en materia de responsabilidad ambiental empresarial. Significar, con carácter previo, que de forma especial es objeto de análisis el tratamiento de la responsabilidad objetiva con referencia al desarrollo de una actividad empresarial o profesional, capacitada para generar impacto ambiental y, en consecuencia, apreciando el riesgo ambiental de la misma.

2.- Tratamiento legal de la responsabilidad ambiental empresarial en la Ley 26/2007 (LRMA) y su desarrollo reglamentario.

La LRMA, como novedad en nuestro Ordenamiento jurídico, para la prevención y, en su caso, reparación de los daños ambientales, incorpora un régimen de responsabilidad objetiva (sin necesidad que concurra dolo, culpa o negligencia) exigible a los operadores de actividades económicas y profesionales incluidas en el anexo III. En este sentido, el citado régimen legal determina que, con respecto a las actividades económicas y profesionales, la responsabilidad será objetiva, en principio, solamente en lo referente a la adopción de las medidas de prevención y evitación de los daños.

El nuevo régimen de responsabilidad impone nuevas obligaciones a las empresas. La LRMA establece, entre otros deberes asignados al operador y para 
las actividades del anexo III (a partir de los plazos y de los valores que establece la Ley), la constitución por las empresas de garantías financieras obligatorias que aportan la cobertura necesaria para garantizar las posibles obligaciones de prevención y reparación que conlleva el desarrollo de la actividad. Así mismo, en virtud del nuevo sistema, es preciso proceder a la determinación del valor de recuperación, el calificado como valor de los daños ambientales, el "valor de los recursos naturales" (NRDA, Natural Resource Damage Assessment), apreciándose en dos etapas: primera, cuando se constituye la garantía financiera (considerando el concepto de riesgo ambiental); y, segunda, cuando en su caso fuera procedente efectuar la reparación con ocasión del daño producido.

Ahora bien, en primer término, conviene identificar -en la práctica empresarial- a qué sujetos afecta la fórmula legal establecida para la responsabilidad ambiental. Así, en primer término, la LRMA define el concepto legal de "operador" (artículo 2.10) haciendo referencia a "cualquier persona física o jurídica, pública o privada, que desempeñe una actividad económica o profesional o que, en virtud de cualquier título, controle dicha actividad o tenga un poder económico determinante sobre su funcionamiento técnico". Para su determinación se tendrán en cuenta los criterios fijados en la legislación sectorial para la determinación del concepto de "titular". Por su parte, en materia de contratación administrativa, si hubiera gestión indirecta se considera operador al contratista.

El capítulo II de la LRMA establece las reglas que operan para proceder a la atribución de responsabilidades. En concreto, el artículo 9 impone la obligación de los operadores que realizaran actividades económicas o/y profesionales de adoptar las medidas preventivas, de evitación y de reparación, así como las medidas para sufragar el coste de las mencionadas, cuando así resulte como efecto de la aplicación de la ley. Sumado a lo anterior, se impone al operador el deber de colaboración con la Administración y el deber de comunicación, con respecto a cualquier daño, amenaza o riesgo ambiental, de los que pudiera tener conocimiento en virtud del desarrollo de la actividad de la que es titular, agente o gestor responsable.

En este aspecto, conforme al marco de atribución de responsabilidades fijado por la LRMA (art. 9), las obligaciones de los operadores se concretan en los siguientes contenidos:

a) Adoptar y ejecutar las medidas de prevención, de evitación y de reparación de daños ambientales y sufragar los costes de las mismas, cualquiera que fuese su cuantía, cuando resulten responsables de los mismos.

b) Comunicar de forma inmediata a la autoridad competente la existencia de daños ambientales o la amenaza inminente de dichos daños, que hubieran ocasionado o que pudieran ocasionar.

c) Colaborar con la Administración pública en la definición de las medidas reparadoras y en la ejecución de las adoptadas. 
El legislador refuerza el criterio del carácter objetivo de la responsabilidad ambiental del operador. Estableciendo una presunción de cumplimiento de los requisitos o condiciones impuestas por los títulos administrativos obligatorios para el inicio y desarrollo de las actividades del anexo III, sin exonerar al operador de la responsabilidad en la que pudiera incurrir. Si bien, dicha presunción no opera en los supuestos del artículo14 de la LRMA ("Inexigibilidad de la obligación de sufragar los costes"), en concreto: a) Con motivo de la actuación de un tercero ajeno a la organización de la actividad (existiendo, en todo caso, medidas de prevención y de seguridad adecuadas). Y, b) con motivo del cumplimiento de una orden o instrucción obligatoria dictada por una autoridad pública competente. Así, los artículos 14 -apartados 1, 2 y 3 - y los artículos 15 y 16 refieren los casos en los que el operador no estaría obligado a cubrir los costes de las medidas preventivas y reparadoras adoptadas. Cuestión distinta será determinar, en la práctica, la concurrencia o no de la responsabilidad empresarial efectiva en cada caso concreto.

Además, la LRMA incorpora unas reglas específicas para determinados supuestos (artículos 10 a 13 LRMA), conforme sigue:

a) Responsabilidad de grupos societarios (siendo de aplicación el artículo 42.1 del Código de Comercio), preceptuando que podrá extenderse la responsabilidad a la sociedad dominante, cuando la autoridad competente aprecie instrumentalización o utilización abusiva de la persona jurídica o fraude de ley.

b) Pluralidad de responsables, aplicable el criterio de la responsabilidad mancomunada, salvo ley especial.

c) Por otro lado, se fijan reglas adicionales para proceder a la identificación de los sujetos obligados al pago de deudas en supuestos de muerte o extinción del operador/es responsable/s, determinando que se transmiten sus obligaciones y deberes, conforme a lo dispuesto para las obligaciones tributarias.

d) Determinación de responsables solidarios y subsidiarios: Tributaria); y,

Responsables solidarios (conforme al artículo 42. 2 de la Ley General

Responsables subsidiarios: gestores y administradores de hecho y de derecho de personas jurídicas responsables, así mismo de aquellas que hayan cesado en sus actividades (en cuanto a los deberes y obligaciones pendientes en el momento del cese). Idem, integrantes de administraciones concursales y liquidadores. Quienes sucedan por cualquier título al responsable.

Las mencionadas responsabilidades pecuniarias se declararán y exigirán en los procedimientos de ejecución previstos en la Ley, en los términos fijados en la normativa tributaria y de recaudación de ingresos públicos.

Señalar que, en principio, la determinación de los operador/es responsables de la contaminación de carácter difuso o, en su caso, del deterioro ambiental producido, resultará procedente -conforme al sistema fijado- en aquellos casos en 
que fuera viable la identificación del agente como causante del daño. En este sentido, la LRMA determina de forma expresa "cuando sea posible establecer un vínculo causal entre los daños y las actividades de operadores concretos". No obstante, en principio, podría interpretarse que en el supuesto de las actividades del Anexo III actividades para las que se fija un régimen de presunción de causalidad-no resultaría necesaria probar la existencia del nexo causal. Ahora bien, lo afirmado quedaría condicionado a que la actividad en cuestión fuera propicia -"actividad apropiada"para generar daño o riesgo ambiental.

Por tanto, el marco de responsabilidad ambiental en la LRMA se concreta en base a las dos modalidades de responsabilidad, conforme sigue:

A) Responsabilidad objetiva: aplicable, en principio, a las actividades indicadas en el Anexo III LRMA (artículo 3.1) en relación con la Ley de IPPC ${ }^{3}$ (v.gr., gestión de residuos, vertidos a las aguas superficiales y subterráneas, sustancias peligrosas, organismos genéticamente modificados, entre otras).

B) Responsabilidad subjetiva: aplicable a las restantes actividades (excluidas o no enumeradas en el Anexo III), concurriendo dolo, culpa o negligencia (si no se hubieran adoptado medidas de prevención y de evitación).

\section{3.- Consideración del riesgo ambiental a efectos de atribución de la responsabilidad en el ámbito de la nueva gobernanza corporativa.}

En principio, considerando el daño ambiental como aquel efectivamente producido y, por su parte, interpretando el concepto de riesgo ambiental como el "riesgo de contaminación ambiental", aquel en virtud del cual pudiera incurrirse en responsabilidades legales por los impactos y efectos perniciosos (en términos económicos "externalidades negativas") que las actividades pueden generar por contaminación ambiental. Así, se estima la necesidad de identificar y valorar el impacto ambiental a efectos jurídicos; por tanto, el riesgo ambiental de las instalaciones y de las actividades empresariales. Motivando, en consecuencia, la articulación de "sistemas jurídicos de responsabilidad ambiental" específicos, configurándolos como complemento indispensable dentro del marco de los instrumentos aplicables para garantizar la tutela jurídica efectiva del medio ambiente.

Conforme se ha avanzado en la presentación de este estudio, es un hecho cierto que en los últimos años, tanto en el ámbito internacional como en el europeo, se ha producido una evolución de los planteamientos culturales, estratégicos y de gobernanza corporativa ${ }^{4}$ (pública y privada); que ha inspirado la labor de

\footnotetext{
${ }^{3}$ Ley 16/2002, de 1 de julio, de Prevención y Control Integrados de la Contaminación (Anexo I). ${ }^{4}$ En este sentido, resultan de interés los trabajos de ORTíZ GARCÍA, Mercedes: "Gobernanza y sostenibilidad", R. Revista de Estudios de la Administración Local, núm. 289/2002, pp.91-139. AA.VV: "Gobernanza para el Desarrollo Sostenible", Cuadernos de Sostenibilidad y Patrimonio Natural, 7/2005, Fundación Santander Central Hispano. PÉREZ CARRILLO, Elena F. (coord.- AA.VV.): Gobierno corporativo y responsabilidad social de las empresas, (economía \& derecho) Marcial Pons, Madrid 2009. TEJERA OLIVER, José Luis: "I+D+i, sostenibilidad y competitividad: III.- La responsabilidad social y su
} 
creación normativa. En paralelo, se han instrumentalizado fórmulas técnicas y jurídicas preventivas, propugnando la implementación de nuevos modelos económicos y empresariales más acordes con la ética y principios del crecimiento sostenible.

Conforme a la evolución producida, en la actualidad, queda patente la adopción de fórmulas legales para asegurar la internalización de los riesgos ambientales en relación a la propia actividad económica que los genera y, al mismo tiempo, garantizar la co-responsabilidad. Con esta legítima pretensión, se han configurado sistemas que impliquen a todas las partes potencialmente responsables, con base en regímenes de derecho privado y/o público, modelos mixtos, imponiendo la obligación de indemnizar por los efectos o consecuencias perniciosos imputables a la producción o emisión de contaminantes.

En el ámbito del Derecho Privado, en materia de responsabilidad civil por daños ambientales y/o contaminación ambiental (daños producidos en recursos naturales y costes de restablecimiento y/o recuperación), se ha pretendido establecer nuevos institutos legales para completar la normativa tradicional en materia de los "daños clásicos" (v.gr., daños patrimoniales y daños a las personas, entre otros). Sin embargo, la práctica ha demostrado que las fórmulas jurídicas tradicionales aplicadas, por sí mismas, no siempre resultan eficaces. Por este motivo, es necesario reforzar y completar las medidas de supervisión y las medidas de ejecución con respecto al cumplimiento del deber de indemnizar por daños ambientales.

La tendencia predominante en los sistemas legales actuales es fijar como criterio preferente la responsabilidad objetiva para los operadores de actividades potencialmente peligrosas; estableciendo determinadas causas de exoneración limitada. Conforme a esta consideración, el modelo aplicable más generalizado en los países desarrollados y con Ordenamientos jurídicos más avanzados se basa en sistemas regulatorios mixtos, de última generación y nuevo enfoque normativo. Sistemas que exigen la co-responsabilidad de los poderes públicos y los agentes privados implicados. Configurados otorgando a las autoridades administrativas competentes la potestad para dictar medidas obligatorias de prevención, medidas correctoras, actuaciones para descontaminar y para reparar el daño causado. Del mismo modo, caso de incumplimiento, proceden sanciones administrativas y/o sanciones penales por incumplimiento grave, así como la exigencia de responsabilidad civil por daños y perjuicios. Por último, en algunos sistemas jurídicos, la responsabilidad por los costes derivados de las medidas de prevención y de recuperación se establecen a cargo de los titulares o, en su caso, ocupantes, de la propiedad, lugar o entorno afectado/contaminado.

Así, en la actualidad, se confirma la preferencia por modelos jurídicos mixtos ${ }^{5}$,

normalización", en el monográfico titulado "Calidad, normalización y competitividad" (AA.VV.), Revista del Instituto de Estudios Económicosn ${ }^{\circ} 4 / 2009$, IEE, pp. 201 y 212-215.

${ }^{5}$ Precisamente para superar las posibles dificultades prácticas que conlleva el tratamiento jurídico de la responsabilidad por riesgos ambientales, la Comisión Europea, después de un destacado 
por su eficacia para proceder a la asignación del riesgo ambiental, combinando normas de responsabilidad de derecho privado -civil- y de derecho público -administrativo- lo que permite cumplir con los criterios internacionales y europeos con respecto al principio contaminador-pagador ${ }^{6} \mathrm{y}$, al mismo tiempo, cumplir con los estándares de prevención, control, reparación e indemnización.

Ahora bien, en todo caso, conviene considerar que la eficacia de cualquier sistema de responsabilidad no es absoluta, pues puede quedar perjudicada en

trabajo previo desarrollado en los últimos diez años y documentos preparatorios emitidos (v.gr., documentos precedentes no normativos, cabe citar el Libro Verde y el Libro Blanco sobre Responsabilidad Ambiental, sirviendo para demostrar la evolución producida), en la Directiva 2004/35/CE del Parlamento Europeo y del Consejo, de 21 de abril de 2004, sobre Responsabilidad medioambiental en relación con la prevención y reparación de daños medioambientales, con la finalidad de fijar un modelo jurídico eficaz y armonizado que supere las fórmulas jurídicas tradicionalmente aplicadas en esta materia. Sin duda, en la práctica, la fórmula jurídica europea adoptada no resolverá todos los supuestos de responsabilidad ambiental, pero en todo caso sí puede interpretarse como una solución equilibrada y propiciatoria de un marco común que aporta transparencia y seguridad jurídica. Así pues, en España suceden varios borradores y anteproyectos de ley que no llegaron a buen término (v.gr., Anteproyecto de Ley de responsabilidad civil derivada de actividades con incidencia ambiental) pero en su caso fueron de interés para propiciar el debate y el estudio de la cuestión. Felizmente, en el año 2007 es promulgada la LRMA española, que traspone la precitada Directiva europea, incorporando a nuestro Ordenamiento jurídico el actual régimen jurídico de responsabilidad ambiental de carácter objetivo e ilimitado basado en los principios de prevención y de que "quien contamina paga" (Preámbulo de la Ley 26/2007, de 23 de octubre, de Responsabilidad Medioambiental, LRMA). Si bien, en la práctica supone un régimen mixto aplicando las dos modalidades de responsabilidad. En todo caso, la aplicación de un modelo mixto de responsabilidad ambiental se ha considerado como un fórmula o sistema más completo, más garante, más apropiado para cumplir su finalidad y, por tanto, más eficaz, al menos en términos relativos (superando las posibles deficiencias que pudieran derivarse de un régimen jurídico exclusivamente basado en la responsabilidad civil por daños ambientales). Así, en todo caso, ya existían pronunciamientos precedentes y antecedentes prácticos en este sentido, entre otros, citar en el ámbito europeo: "El sistema que propone la Comisión Europea en el Libro Verde sobre Responsabilidad Ambiental es un sistema mixto que combine el mecanismo de la responsabilidad civil con un sistema colectivo de cobertura, y este último actuaría de forma subsidiaria respecto al primero. Así en los supuestos en que pudiese ser determinado el sujeto responsable del daño, se le obligaría a repararlo mediante la responsabilidad civil y en los casos en los que no fuera viable esta identificación se aplicaría el sistema colectivo de compensación y se harían a cargo de la reparación del daño los miembros del sector relacionado con dicho daño". Los cuales, a su vez, podrían repetir contra el causante del mismo si pudieran identificar en algún momento al causante. "El sistema propuesto, en su momento, por la Comisión europea no tiene sólo en cuenta el aspecto reparador de la responsabilidad civil, sino que también se refiere al aspecto preventivo." (op. cit., pp. 54 y 56, CANTALAPIEDRA LÓPEZ, O.: "Seguros Ambientales", Derecho Ambiental, Revista Jurídica General, boletín del Il. Colegio de Abogados de Madrid, núm. 18, $3^{a}$ época, mayo 2001, pp. 35-72).Por otra parte, citar en España el PERMA, Pool Español de Riesgos Ambientales, que en su ya larga práctica, inicialmente apuntó y desarrolló la opción del sistema mixto para cubrir mediante los siniestros ambientales. El citado POOL es una Agrupación de Interés Económico constituida en 1994 para administrar un convenio de correaseguro, para la suscripción conjunta de los riesgos medioambientales. El convenio acoge tanto a compañías aseguradoras como reaseguradoras (www.perm.es).

${ }^{6} \mathrm{El}$ "principio de quien contamina paga" representa uno de los principios rectores que fija la OCDE con referencia a los Aspectos Económicos Internacionales de la Políticas Ambientales. 
determinados supuestos que ofrezcan dificultades probatorias. En algunos casos, motivadas por la propia complejidad de los daños ambientales; ; en otros, por la imposibilidad de determinar el sujeto o sujetos responsables. Incluso, casos en que no fuera viable la identificación del agente contaminante, entre otros. Incluso, supuestos de insolvencia del sujeto/operador u operadores responsable o responsables, entre otros.

En este sentido, a los efectos citados, resultará de suma utilidad el estimar pertinente una consideración amplia sobre la validez y la apreciación de los medios probatorios, admitiendo "otros documentos" a tales efectos. Así, además de informes técnicos, pólizas, coberturas, otros informes y acreditaciones específicas conforme a instrumentos de normalización o estándares reconocidos ${ }^{8}$. Pudiendo, de este modo, estimar el valor de instrum ${ }^{9}$. Pues siendo, todo ellos, de carácter técnico también es cierto que producen efectos jurídicos valorables. Señalar, motivando el planteamiento

\footnotetext{
${ }^{7}$ En este punto, añadir a lo mencionado en el texto, las dificultades que en algunos casos prácticos conllevan las propias características del daño ambiental. Conforme advierte E. PAVELEK, al referirse a las dos características principales de la responsabilidad civil por daños ambientales que precisamente hacen que no resulte suficiente la aplicación del régimen general de la responsabilidad civil tradicional, señala que una de las citadas dos características "...que hace que los daños ambientales necesiten un tratamiento específico es la posibilidad de que se manifiesten a lo largo de un período muy dilatado de tiempo". (PAVELEK, E.: Estudios sobre responsabilidad civil medioambiental y su aseguramiento.Lacobertura delriesgomedioambientalenlaspólizas deresponsabilidadcrillgeneral Ed EspañoladeSeguros,SL, Madrid 1997, pp. 202-205, op. cit. p. 49, CANTALAPIEDRA LÓPEZ, O.: "Seguros Ambientales", Derecho Ambiental, Revista Jurídica General, boletín del Il. Colegio de Abogados de Madrid, núm. 18, $3^{\mathrm{a}}$ época, mayo 2001, pp. 35-72). Así mismo, considerar, lo advertido por O. CANTALAPIEDRA en el artículo citado (p. 51): "Las propias peculiaridades del daño ambiental en sentido estricto (perturbaciones que afectan sólo a los recursos naturales) obligarían al responsable de los daños, no sólo a indemnizar, que es la finalidad propia del seguro, sino a reponer las cosas a su estado original, por ejemplo la descontaminación de un suelo contaminado. Ya no hablamos sólo de obligaciones de pecuniarias sino de una obligación de hacer".

${ }^{8}$ En la actualidad, en este sentido, destacan distintas iniciativas en el marco de la gestión de la Responsabilidad Social de la Empresa (RSE) en el ámbito internacional, con el propósito de facilitar el cumplimiento de todos los aspectos que integra la misma, en el ámbito de la gestión y la estrategia empresarial. En este sentido, entre otras iniciativas, citar las basadas en los sistemas de autodeclaración (reporting) de las empresas, como son las "memorias de sostenibilidad", v.gr., conforme a la utilización de modelos normalizados o estándares, como el propiciado por el Global Reporting Initiative (GRI); otras ligadas a sistemas de calificación (accountability), como por ejemplo la AA1000; y otras aportadas por los organismos de normalización, comola ISO (International Organization for Standarization) o el Instituto Australiano (AS8000). En esta materia, DOPAZO, R: Memorias de sostenibilidad y responsabilidad empresarial, Universidad de Alicante, 2009. TEJERA, J.L.: "I+D+i, sostenibilidad y competitividad", IEE, nº 4/2009, Calidad, Normalización y Competitividad, p.212-215).

${ }^{9}$ Avalando lo expuesto en el texto, se ha pronunciado la doctrina jurídica más avanzada, reforzando la consideración y valoración de las evaluaciones y auditorías (conforme a sus distintos tipos y, en especial, en materia de calidad y medio ambiente) a todos los efectos. Destacando, la evaluación y la acreditación por entidades públicas y por entidades privadas. Así mismo, los supuestos del ejercicio por las entidades o empresas de fórmulas admitidas de autoevaluación y autocontrol; completando, de este modo, la actividad de autoregulación (refiriéndose a esta última como una modalidad de producción de normativa, en concreto, de normativa técnica) que realizan los organismos competentes designados o reconocidos oficialmente. SÁNCHEZMORÓN, M.: Derecho Administrativo. Partegeneral. Ed. Tecnos, Madrid
} 
expuesto, que la determinación de los medios de prueba ${ }^{10}$ apropiados en cada caso deberá ser congruente con la propia complejidad del riesgo ambiental (tipología, identificación, evaluación, valoración y tratamiento) y de los denominados riesgos del desarrollo ${ }^{11}$ (conforme al estado de la ciencia y de la técnica).

En este sentido, la LRMA parece haber generado aportaciones de interés, a tenor del análisis de su desarrollo reglamentario, al que posteriormente se hace referencia. Abordando esta cuestión, examinar el valor de determinadas herramientas técnicas y jurídicas, como las expuestas en el anterior párrafo, en especial a los efectos prácticos de preconstituir la prueba. Por ejemplo, la referencia expresa que

2008, pp.644, 658-661. En este ámbito, destacar el supuesto de la actividad de supervisión y control realizada a de entidades privadas en materia de seguridad y calidad industrial, con base legal en la Ley 21/1992, de 16 de julio, de Industria. Así, señalar los controles realizados por organismos competentes reconocidos oficialmente, organismos de control autorizados o acreditados. Entidades con demostrada capacidad técnica y apropiada infraestructura, cumpliendo requisitos de solvencia e imparcialidad. Para ejercer las funciones mencionadas, dichos organismos precisan autorización administrativa; así, requieren previamente su verificación, realizada por entidades acreditadoras. Otro ejemplo de ejercicio de supervisión y control por terceros independientes (entidades privadas) que certifican la conformidad con respecto al cumplimiento de normas técnicas (v.gr., normalización en materia de seguridad y calidad industrial y, en el mismo sentido, en materia de garantía de la calidad ambiental), citar en España, entre otras entidades y a modo de ejemplo, AENOR (Asociación Española de Normalización y Certificación). Por último, completando los supuestos expresados, añadir los supuestos de autoevaluación y autocontrol realizados voluntariamente por las empresas/ industrias/organizaciones, cumpliendo requisitos técnicos y jurídicos, por ejemplo, referencia al Sistema europeo de gestión y auditoría ambiental (EMAS) y, por otro lado, el Sistema europeo de etiquetado ecológico (EEE). Referencias de interés en las obras magistrales de MARTíN MATEO, R:: Nuevosinstrumentos para la tutela ambiental, Madrid 1989. Idem,Elmarco público dela economía de mercado, Madrid 1999. ARANGÜENA PERNAS, A.: Auditoría medioambiental en la empresa, Madrid 1994. IZOUIERDO CARRASCO, M.: La seguridad delosproductosindustriales, Madrid2000. ÁLVAREZGARCÍA, V::Lanormalización industrial, Valencia 1999. CARRLLODONAIRE, J.A.: El Derecho dela seguridad y dela calidad industrial, Madrid 2000. GARCÍA URETA, A.: La potestad inspectora en el Derecho comunitario, Madrid 2008. ESTEVE PARDO, J.: Técnica, riesgoy Derecho, Barcelona 1999.

${ }^{10}$ Artículos 299 y ss. de la LEC ; artículos 1.216 y ss. del CC y artículo 80.1 LRJPAC, En este sentido, con referencia al procedimiento administrativo, a efectos probatorios se admiten actas y documentos públicos, sólo presumiendo su veracidad (presunción iuris tantum) salvo prueba en contrario. Del mismo modo, resulta habitual aportar informes al procedimiento, que pueden proceder de la Administración o de expertos, personas o entidades ajenas a la Administración, considerándose facultativos y no vinculantes, salvo disposición expresa en contrario (artículo 83.1 LRJPAC).

${ }^{11}$ En relación con el concepto de "riesgos del desarrollo" es necesario hacer referencia al Artículo 3. ñ) de la Ley 16/2002, de 1 de julio, de Prevención y Control Integrados de la Contaminación (IPPC), que aporta la definición legal de "Mejores técnicas disponibles", considerando como tales "la fase más eficaz y avanzada de desarrollo de las actividades y de sus modalidades de explotación, que demuestren la capacidad práctica de determinadas técnicas para constituir, en principio, la base de los valores límite de emisión destinados a evitar o, cuando ello no sea posible, reducir en general las emisiones y el impacto en el conjunto del medio ambiente y de la salud de las personas. Para su determinación se deberán tomar en consideración los aspectos que se enumeran en el anejo 4 de esta Ley." Por su parte, el Anejo 4 de la citada Ley española de IPPC, determina los aspectos a considerar cuando se determinen las mejores técnicas disponibles definidas en el citado art. 3.ñ), apreciando los costes y las ventajas derivadas de una acción y los principios de precaución y prevención. 
realiza la normativa española analizada ${ }^{12}$ con respecto al cumplimiento de normas técnicas ISO 14001 (Sistemas de gestión de la calidad medioambiental) y de normas jurídicas como el Reglamento EMAS ${ }^{13}$.

Así mismo, valorar positivamente la constitución y la aportación de garantías financieras suficientes (voluntarias) por parte del operador. Por tanto, cabe estimar a efectos probatorios no sólo los casos en los que la LRMA exige las garantías legales obligatorias (actividades del anexo III).

\section{4. - Fórmula jurídica adoptada por el legislador: Tipos de responsabilidad en la LRMA.}

Conforme a la práctica desarrollada hasta el momento actual, puede afirmarse que las fórmulas legales aplicadas para asegurar la responsabilidad ambiental no han sido eficaces en términos absolutos, puesto que no han sido de utilidad en todos los casos y, de forma especial, no han servido para prevenir la producción de siniestros con graves efectos para el entorno ambiental. En este sentido, como se ha manifestado en reiteradas ocasiones ${ }^{14}$, el tradicional instituto jurídico de la responsabilidad civil

${ }^{12}$ Citar, a modo de ejemplos, las referencias legales expresas contenidas en el artículo 28 de la LRMA ("Exenciones a la obligación de constitución de garantía financiera"). Por otra parte, otros ejemplos, en el texto reglamentario de la LRMA (Decreto 2090/2008, de 22 de diciembre, que aprueba el reglamento de desarrollo parcial de la LRMA): Artículos 34 y 35 con referencia a la elaboración de análisis de riesgos medioambientales; artículos 45 y 46 (verificación obligatoria del informe de análisis de riesgos y requisitos de los verificadores-acreditados). Así mismo, el Anexo I (Aspectos técnicos para la determinación del daño ambiental) y el Anexo II (Metodología para calibrar las medidas de reparación establecidas - reparación complementaria y compensatoria).

${ }^{13}$ El Reglamento EMAS: Reglamento (CE) No 1221/2009 del Parlamento y del Consejo de 25 de noviembre de 2009 relativo a la participación voluntaria de organizaciones en un sistema comunitario de gestión y auditoría medioambientales (EMAS), DOUE L 342 de 22-12-2009. Estudios sobre los instrumentos de tutela ambiental y, entre otros, analizando los modelos de gestión ambiental, como el sistema europeo EMAS, en: MARTÍN MATEO, R.: Nuevos instrumentos para la tutela ambiental. Ed. Trivium, Madrid 1994.DOPAZOFRAGUÍO, P:El régimenjurídico delasmarcas decalidadambiental:Etiquetaecológicay tutela ambiental. Ed. EXLIBRIS Ediciones, Madrid 2001. NOGUEIRA LÓPEZ, ALBA: "Fomento Público de la Responsabilidad Social Corporativa: Contratación Pública y Sistemas de Gestión Ambiental". En AA.VV. (Elena F. Pérez Carillo, Coord.): Gobierno corporativo y responsabilidad social de las empresas. Ed. Marcial Pons -economía \& derecho-, Madrid 2009, pp. 341-361. NOGEUIRA LÓPEZ, A.: Auditorías ambientales, intervención pública ambiental y autocontrol empresarial, Madrid-Barcelona, Marcial Pons 2000. NOGUERIA LÓPEZ, A.: "La reforma del Reglamento comunitario de ecogestión y ecoauditorías", Revista Aranzadi de Derecho Ambiental (2002), pp. 225-236. Con referencia a otros instrumentos aplicables en los sistemas integrados de gestión medioambiental de interés a los efectos expuestos, analizados en: DOPAZO, P::"Las Nuevas Marcas de Garantía de la Calidad. Aspectos Jurídicos y Supuestos Prácticos", Ponencia en Jomada de Promoción delaPropiedad Industrial y las Nuevas Tecnologías, Uc3m, Madrid, 11 de diciembre de 2008. DOPAZO FRAGUÍO, P.: "Calidad y Excelencia Empresarial a través del Diseño Industrial: EL ECODISEÑO y laECOETIQUETA, Congreso Internacional: El Diseño Industrial como Clave de la Competitividad Empresarial. (Uc3m, DDI y OEPM.), celebrado en Madrid el 3 y 4 de diciembre de 2008, en Actas del Congreso Internacional: DiseñoIndustrial como Clave dela Competitividad Empresarial. (AA.VV.), publicadas en soporte digital-CD, ISBN 978-84-691-6922-3.

${ }^{14}$ En este sentido, los interesantes estudios realizados en la materia por E. PAVELEK, que expone y argumenta la concurrencia de "(.../...) dos características de la responsabilidad civil por daños ambientales que hacen que no se le pueda aplicar el régimen general de la responsabilidad civil. 
por daños ambientales aplicado per se no es suficiente para garantizar la protección ambiental y, en concreto, no es un mecanismo específico, ni apropiado por sí mismo, para prevenir los riesgos ambientales. Por tanto, resulta preciso completar su aplicación con otras figuras jurídicas. Así, la vigente LRMA pretende aportar fórmulas más eficaces, reforzando el enfoque preventivo y ordenando el establecimiento de las garantías necesarias para asegurar, en todo caso, una adecuada reparación ${ }^{15}$.

En este sentido, de la LRMA en algunos aspectos innova y en otros sigue el modelo precedente de la Ley alemana de responsabilidad ambiental de $1990^{16}$. Así,

Estas dos características son: 1. El daño ambiental trasciende del ámbito del Derecho privado puesto que entran en juego bienes de dominio público e intereses difusos (.../...). Además del daño ambiental entendido como impacto a las personas, que son los que las pólizas de responsabilidad civil han venido cubriendo tradicionalmente: a) Daños corporales: referido fundamentalmente a fallecimiento, enfermedades y lesiones. Incluye también los daños morales. b) Daños materiales: menoscabos patrimoniales que se producen en el patrimonio de una persona como consecuencia del siniestro. c) Perjuicios: consecuencia de los anteriores y que se puede manifestar como daño emergente y lucro cesante. (.../...). 2. La segunda característica que hace que los daños ambientales necesiten un tratamiento específico es la posibilidad de que manifiesten a lo largo de un período muy dilatado detiempo." (PAVELEK,E.:Estudiossobre ResponsabilidadCivilMedioambientalysu Aseguramiento. La Cobertura del Riesgo Medioambientalen las Pólizas de Responsabilidad Civil General, Ed. Española deSeguros, S.L., Madrid 1997, p. 202-205). En el mismo sentido, se ha afirmado que "(.../...) la responsabilidad civil es, hoy por hoy, un instrumento cuya primera finalidad no es precisamente la protección del ambiente. (.../...). De no darse el daño, el ordenamiento jurídico dispone de otros medios para reaccionar a través de los Derechos administrativo y penal pero ya no entrará en juego el Ordenamiento jurídico civil, puesto que no es ése su contenido principal." (DE MIGUEL, C.: La Responsabilidad Civil por Daños al Medio Ambiente. Ed. Civitas, Madrid 1997, p. 85-86). Por su parte, se ha afirmado que para lograr que la responsabilidad civil sirva para reparar los daños ambientales tienen que concurrir cuatro presupuestos necesarios: $1^{\circ}$. Nexo causal claro y preciso. $2^{\circ}$. Identificación de los responsables por sus acciones individuales. $3^{\circ}$. Daño cuantificable. $Y, 4^{\circ}$. Perjudicado concreto con un interés legítimo. (JUSTESCRIVÁ, J.J.:Estudiossobrela ResponsabilidadCivil MedioambientalysuAseguramiento. Laobligatoriedadde aseguramiento dela responsabilidad civil por daños almedio ambiente. Ed. Española de Seguros, S.L., Madrid 1997, p. 275). Por otra parte, en concreto con referencia a los tradicionales seguros de responsabilidad civil y a los seguros ambientales aplicables, se ha manifestado que "las pólizas de seguros no cubren todos los riesgos, sino sólo los asegurados y lo mismo ocurre con las pólizas de responsabilidad civil. Además, son dinámicas, es decir, que a medida que van surgiendo dificultades de interpretación y nuevos riesgos, se van modificando. Hasta hace poco tiempo no existían pólizas que se ocupasen de los daños ambientales, únicamente se incluían como un riesgo más dentro de las pólizas de responsabilidad civil de actividades que cubrían todos los riesgos derivados de una empresa. Éstas pólizas de responsabilidad civil general son la denominadas en inglés "comprehensive general liability insurance policies" (C.G.L.). Sólo las pólizas más recientes han dado un tratamiento individualizado a este tipo de riesgos. Los primeros que aparecieron fueron los seguros de contaminación. Éstas pólizas fueron las "Environmental impairment liability policies" (E.I.L.) y nacieron en EE.UU. a finales de los años 70." (CANTALAPIEDRA LÓPEZ, O.: "Seguros ambientales", en el monográfico Derecho Ambiental, Revista Jurídica General, Boletín del Il. Colegio de Abogados de Madrid, núm. 18, $3^{a}$ época, mayo 2001, p. 49).

${ }^{15}$ Vid. Exposición de motivos de la Ley 26/2007, de 23 de octubre, de Responsabilidad Medioambiental (BOE núm. 255, de 24-10-2007) -LRMA-.

${ }^{16}$ La ley alemana de 1990 de responsabilidad ambiental ha significado un gran avance para el Derecho europeo, entre otros motivos, porque aplica el criterio de la responsabilidad objetiva, modificando el clásico planteamiento de la responsabilidad civil, que con carácter general implica imponer a la víctima 
incorpora a nuestro Ordenamiento jurídico un régimen administrativo de responsabilidad ambiental de carácter objetivo e ilimitado basado en los principios de prevención y de que "quien contamina paga". Configurando una fórmula jurídica integradora, que aporta un conjunto de criterios, medidas y potestades administrativas, con cuyo ejercicio la Administración pública debe garantizar el cumplimiento de la ley y la aplicación del régimen de responsabilidad civil clásica. Al mismo tiempo, impone a las empresas la implementación de las herramientas técnicas, jurídicas y financieras necesarias. Por tanto, en la práctica, conlleva marcar nuevos planteamientos, arbitrar nuevas estrategias empresariales y adecuar los modelos de gerencia a tales objetivos.

En concreto, la LRMA española refuerza el carácter objetivo de la responsabilidad ambiental. Estableciendo como criterio general la responsabilidad medioambiental objetiva ${ }^{17}$. Así pues, fija el carácter objetivo de la responsabilidad en las obligaciones de actuación impuestas al operador, con independencia de concurrir dolo, culpa o negligencia que hubiera podido existir en la conducta. De esta forma, el legislador en la LRMA pretende completar el sistema legal de tutela ambiental, ya que tradicionalmente nuestra legislación sectorial y específica sí tipificaba los daños ambientales provocados por incumplimiento de los requisitos legales, por acciones/omisiones infractoras, estableciendo sanciones administrativas y penales. Del mismo modo, la legislación específica ha preceptuado el deber de indemnizar y restituir los perjuicios derivados de dichas actuaciones infractoras.

Al mismo tiempo, interpretar que la LRMA -conforme al modelo descritopretende garantizar el cumplimiento del principio "quien contamina paga" en relación con la necesidad de adoptar un modelo integrado de gestión empresarial responsable y sostenible. En virtud de lo expresado, el legislador aporta una fórmula para hacer efectivo el poder trasladar los costes derivados de la reparación de los daños ambientales desde la sociedad hasta los titulares u operadores económicos beneficiarios de la explotación de los recursos naturales.

Así, la LRMA vigente propugna la reparación total del medio dañado; el restablecimiento del medio y la recuperación de los recursos naturales. Con todo, se incrementa la consideración del propio "valor ambiental" como bien jurídico digno

la carga de la prueba de la relación de causalidad. La ley alemana establece una presunción respecto a la causa del daño ambiental: la instalación en la que acontece la actividad apropiada o adecuada para causarlo. Referencias al antecedente de la Ley alemana, entre otros, citar los estudios de CANTALAPIEDRA LÓPEZ, O.: "Seguros ambientales", en el monográfico Derecho Ambiental, Revista Jurídica General, Boletín del Il. Colegio de Abogados de Madrid, núm. 18, $3^{a}$ época, mayo 2001,p. 6466. SALJE, P. y PETER, J.: Umwelthaftungsgesetz, ed. Beck, Munich 2005, op.cit., ESTEVE PARDO, J.: Ley deResponsabilidad Medioambiental. Comentariosistemático. Ed. Marcial Pons, Madrid2008, p. 58.

17 "De entrada debe destacarse que el régimen de responsabilidad objetiva que la propia LRMA proclama en su Preámbulo se proyecta exclusivamente como ya sabemos sobre una serie de actividades tasadas: las que figuran en el Anexo III de la Ley cuya relación puede ampliarse por las Comunidades Autónomas. En las restantes actividades desarrolladas por los operadores, la responsabilidad, o más precisamente la obligación de reparación, sólo es exigible cuando media 
de protección, por lo que no se considera suficiente la indemnización económica para responder por los daños producidos y repercutidos.

Por tanto, insistiendo en la obligatoriedad del enfoque preventivo propugnado por el legislador, resulta relevante a los efectos de la cuestión formulada, el deber de exigir al operador una previa identificación y evaluación del riesgo ambiental (análisis de riesgos) de forma efectiva, conforme a la exigencia de verificación por tercero imparcial e independiente. Tal y como prescribe la normativa vigente. Si bien, en nuestra opinión, dicha exigencia no debería ser interpretada de una forma restrictiva, en aras del interés público. Por cuanto, puede apreciarse que la herramienta técnica del análisis de riesgos, entre otras, será de gran utilidad práctica a efectos preventivos. En efecto, en este aspecto, destacar la implementación de un sistema integrado de gestión de riesgos y responsabilidad social corporativa o empresarial ${ }^{18}$-RSC/RSE- conforme a un modelo avanzado de Gobierno Corporativo.

En conclusión, la exigencia legal prevista es valorable de forma positiva a todos los efectos. Lo que significa considerar como oportuna una posible aplicación de la herramienta del análisis de riesgos ambientales a la práctica de todas las actividades (incluidas o excluidas en el Anexo III de la LRMA).

\section{5.- Análisis de Riesgos Ambientales.}

La herramienta del análisis de riesgos es un instrumento clave aplicado en el ámbito de la gestión de riesgos. Lo que significa, que toda organización o empresa debe proceder a la elaboración previa de un análisis de todos los riesgos (incluidos los ambientales) a los que está expuesta su actividad o que puedan derivar del desarrollo de la misma. Así, resulta necesario identificar y valorar los riesgos de forma previa y regular su actualización. Para lo cual es imprescindible elaborar un "mapa de riesgos" completo, que incluya los riesgos ambientales de forma clara, veraz y específica. Además, los citados riesgos han de considerarse no de forma individual sino de forma integrada. Lo que significa, su estimación no sólo de forma aislada sino también en relación con otros tipos de riesgos empresariales; para así observar sus implicaciones y efectos sobre la empresa y su entorno. Añadir, en este punto, el cumplimiento del deber de transparencia informativa.

De este modo, el marco normativo vigente obliga a la realización y presentación del "análisis de riesgos medioambientales", configurándolo como pieza clave para la valoración del riesgo ambiental. Al mismo tiempo, el valor instrumental del citado medio ha quedado confirmado en la práctica, desde la perspectiva de una buena gestión estratégica empresarial. Por tanto, incorporar la gestión de riesgos ambientales (GRA) permitirá al empresario estar preparado para el desarrollo eficiente

\footnotetext{
${ }^{18}$ En materia de modelos de RSE, mencionar el interés de los trabajos que siguen: ALMAGRO, Juan José:AproximaciónalaResponsabilidadSocialdelaEmpresa:reflexionesypropuestadeunmodelo. Colección Cuademos de la Fundación, $n^{\circ}$ 132, Fundación Mapfre, Madrid 2009. VOLLÚ DA SILVA FILHA, Teresina: Responsabilidadesocialempresarialnomercadodesegurosbrasileiroinfluenciasculturaiseimplicaçoesrelacionais. Colección Cuadernos de la Fundación n 113, Fundación Mapfre, Madrid 2007.
} 
de la actividad conforme al cumplimiento de los requisitos legales.

Además, resultará preciso demostrar la realización del estudio y la valoración del riesgo para cumplir con la constitución de garantías "válidas" y "suficientes" en cada caso. De esta forma, la LRMA exige el requisito de la verificación del análisis de riesgos realizado por el operador. En este sentido, en el Capítulo III del Reglamento de la LRMA hace referencia expresa al deber del operador de realizar y presentar -validado/verificado- un análisis de riesgos ambientales referido a la actividad que ejercita (artículos 33, 34 y 35).

Por tanto, en la actualidad, resulta preciso integrar adecuadamente un modelo propio de "gestión integrada de riesgos ambientales" en la empresa ${ }^{19}$. De este modo, la gerencia de riesgos ambientales -a cargo del operador- integra un proceso que conlleva las siguientes actuaciones: planificar, organizar, dirigir y controlar los recursos y actividades de la empresa para minimizar los efectos adversos de los sucesos accidentales que afecten a la misma, al menor coste posible. Siendo los principales hitos del citado proceso: identificación del riesgo, evaluación, gestión del riesgo, mejora y tratamiento del riesgo.

En relación con lo expuesto, el Capítulo IV de la LRMA establece tres modalidades de garantías financieras obligatorias, compatibles y complementarias, que deben ser suscritas por el operador u operadores (artículos 24 a 34) con la finalidad de constituir una garantía válida y suficiente, para dar cobertura a la responsabilidad del operador. Precisamente, para determinar y concretar en cada caso la cuantía de la garantía (suficiencia) resulta preciso considerar los resultados del análisis de riesgos efectuado con respecto a la actividad empresarial, industrial o profesional concreta; comprobando su adecuada validación y actualización. Así, desarrollando los mencionados preceptos, el Reglamento ${ }^{20}$ de la LRMA, refiere la obligatoriedad de la herramienta expresada -el análisis de riesgos- que persigue como objetivo el posibilitar la constitución y la propia operatividad de las garantías financieras exigidas por el legislador.

Añadiendo, que dicho análisis una vez emitido deberá ser verificado por un organismo acreditado oficialmente (artículos 34 y 35, en el Capítulo III relativo a los aspectos referentes a las garantías financieras obligatorias del Reglamento de la LRMA). El Reglamento de la LRMA precisa que el instrumento y metodología del análisis de riesgos medioambientales será realizado por el operador o un tercero contratado por éste, siguiendo el esquema establecido por la Norma UNE $150.008 \mathrm{u}$ otras normas análogas. Aplicando los criterios recogidos en el capítulo II ("Reparación de los daños medioambientales") con respecto a los parámetros fijados en el propio artículo 34.

\footnotetext{
${ }^{19}$ En esta materia, la conferencia de DOPAZO FRAGUíO, Pilar: "La gestión integral de riesgos en el entorno de la PYME actual (riesgos operativos y tipología)", en Jornada Fundación Mapfre "La Cultura de la gerencia deriesgosen la Pyme", Madrid 1/12/2009.

${ }^{20}$ Real Decreto 2090/2008, de 22 de diciembre, por el que se aprueba el Reglamento de desarrollo parcial de la Ley 26/2007, de 23 de octubre, de Responsabilidad Medioambiental (BOE núm.308, de 23 de diciembre de 2008).
} 
En este sentido, la norma técnica UNE 150008:2008 "Análisis y evaluación del riesgo ambiental" facilita la implementación de un modelo propio de gestión del riesgo, por cuanto permite establecer unos criterios y una metodología aplicable, para la identificación de causas/sucesos básicos (escenarios causales); sucesos iniciadores y frecuencia de los sucesos iniciadores; factores condicionantes; escenarios del siniestro, accidente y consecuencias del mismo ${ }^{21}$. Por último, con carácter general, resulta preciso hacer referencia a la norma técnica internacional ISO 3100:2009 en el ámbito de la Gerencia de Riesgos ${ }^{22}$ y la ISO 31010 que aborda las técnicas de evaluación de riesgos.

\section{6. - Garantías financieras obligatorias.}

Conforme se ha avanzado en el anterior apartado, el legislador establece la obligatoria constitución de una garantía financiera a cargo de los operadores de las actividades del anexo III (artículo 24 LRMA) ${ }^{23}$. El capítulo III del Reglamento de la LRMA, titulado "Garantía financiera obligatoria", desarrolla las modalidades y los presupuestos necesarios para la constitución de dicha garantía. Con respecto al requisito de la suficiencia, se establece que la determinación de la cuantía será en función del riesgo de la actividad. En este sentido, observar que en todo caso la garantía suscrita deberá ser válidamente constituida y suficiente para cumplir su finalidad: garantizar la responsabilidad ambiental del operador. Por tanto, una vez constituida, la garantía quedará afecta de forma exclusiva a la cobertura de posibles responsabilidades ambientales del operador, derivadas de su actividad. Advirtiendo que la garantía no limitará la responsabilidad del operador.

En consecuencia, la presentación de dicha garantía resulta precisa para la concesión de las autorizaciones ambientales de las actividades del citado anexo III. Interpretando, v.gr., que así opera tanto en el caso de la "Autorización Ambiental Integrada" -AAI- ${ }^{24}$ (instalaciones de titularidad pública o privada en las que se desarrolle alguna de las actividades industriales incluidas en el anejo 1 de la Ley 16/ 2002). Y, del mismo modo, considerar su exigencia en el supuesto de las "Autorizaciones sustantivas" (industrias o instalaciones industriales sometidas a autorización administrativa previa, conforme al art. 4 de la ley 21/1992, de 16 de julio, de Industria, con carácter general).

\footnotetext{
${ }^{21}$ Resulta de interés consultar, a modo de ejemplo y práctica, la "Guía para la realización del Análisis del Riesgo Medioambiental en el ámbito del Real Decreto 1254/1999, Seveso II", publicada por la Dirección General de Protección Civil del Ministerio del Interior, Madrid 2004.

${ }^{22}$ ESCORIAL, A.: "Ver la luz la nueva ISO 31000 sobre Gerencia de Riesgos", Aseguranza, n¹45, diciembre 2009, p.18.

${ }^{23}$ Vid., Disposición final cuarta de la LRMA, con respecto a la "Aplicación de la garantía financiera".

${ }^{24}$ Con respecto al concepto legal y marco regulador de la AAI, véase (Ley de IPPC) Ley 16/2002, de 1 de julio, de prevención y control integrados de la contaminación (BOE núm. 157, de 2 de julio) y el Real Decreto 509/2007, de 20 de abril, por el que se aprueba el Reglamento para el desarrollo y ejecución de la Ley 16/2002, de 1 de julio, de prevención y control integrados de la contaminación. En el Anexo 1 de la citada Ley se establece la lista de actividades industriales a las que será aplicable el régimen de IPPC, exigiendo la referida AAI.
} 
Las modalidades de garantías financieras que establece la LRMA son: la póliza de seguro, el aval bancario y la constitución de una reserva técnica mediante la dotación de un fondo "ad hoc" con materialización de inversiones financieras respaldadas por el sector público. Las garantías expresadas pueden constituirse de forma alternativa o complementarias entre sí, de este modo se pretende garantizar el requisito de la suficiencia y de la eficacia de las mismas a los fines previstos.

Por otra parte, se establecen los tres supuestos que constituyen exenciones legales a la obligación de constituir la garantía (artículo 28 LRMA). En especial, resulta de gran interés destacar la letra b), "Los operadores de actividades susceptibles de ocasionar daños cuya reparación se evalúe por una cantidad comprendida entre 300.000 y 2.000.000 euros que acrediten mediante la presentación de certificados expedidos por organismos independientes, que están adheridos con carácter permanente y continuado, bien al sistema comunitario de gestión y auditoría medioambientales (EMAS), bien al sistema de gestión medioambiental UNE-EN ISO 14001:1996".

\section{7. - Causas de exoneración de la responsabilidad.}

Al analizar la LRMA en este punto conviene previamente precisar el tratamiento dado a las siguientes cuestiones, diferenciando: A) Causas excluidas del régimen de responsabilidad de la Ley (Artículo 3.4 y Disposición Adicional 2a.5. de la LRMA). B) Causas que conllevan la inexigibilidad de la obligación de sufragar los costes (Artículo 14.1. y 2. LRMA). Y, por último, C) Recuperación de los costes en los casos de inexigibilidad de la obligación de sufragar los costes (Artículos 14.3. y 15 LRMA).

Así pues, con respecto a las causas excluidas de la aplicación del marco legal, el art. 3.4 de la LRMA dicta las causas extraordinarias y excepcionales en las que "no será aplicable a los daños medioambientales, ni a las amenazas inminentes de que tales daños se produzcan cuando hayan sido ocasionados por alguna de las siguientes causas: a) Un acto derivado de un conflicto armado, de hostilidades, de guerra civil o de una insurrección. b) Un fenómeno natural de carácter excepcional, inevitable e irresistible. c) Las actividades cuyo principal propósito sea servir a la defensa nacional o a la seguridad internacional, y las actividades cuyo único propósito sea la protección contra los desastres naturales." (Este último apartado es completado con lo expuesto en la Disposición Adicional Segunda, apartado 5, de la LRMA ${ }^{25}$ ).

Con referencia a las otras causas contenidas en el artículo 3 en su apartado 5 , que suponen excepciones a la aplicación de régimen de responsabilidad, afirmar que sí podrían ser cuestionadas en algunos casos o, al menos, suscitar dudas interpretativas en la práctica. Las excepciones contempladas son: a) Los daños medioambientales y las amenazas inminentes producidas con origen en un suceso derivado, relacionado o, en su caso, "amparado" por un compromiso internacional

\footnotetext{
${ }^{25}$ Disposición Adicional Segunda. 5. (LRMA):"Los daños medioambientales producidos por las actividades cuyo principal propósito sea servir a la defensa nacional o a la seguridad internacional quedan excluidos de los desarrollos legislativos posteriores a que hacen referencia los apartados anteriores."
} 
asumido -derivado de convenios internacionales del anexo IV-. b) Los riesgos nucleares, daños ambientales o amenazas inminentes de daños que se produzcan, causados por actividades que utilizan materiales objeto del Tratado constitutivo del $\mathrm{CE}$ de la Energía Atómica y regulación específica europea y/o con referencia a convenios internacionales del Anexo V.

En todo caso, el criterio que puede inferirse como denominador común motivador de los supuestos o causas citadas, podría radicar en que el legislador ha estimado, como necesario y "justificado", imponer para determinados supuestos un deber de tolerancia en interés general. Considerando, por tanto, que en dichos supuestos -en principio- no existiría una responsabilidad concreta imputable a operadores o a terceros, privados o públicos. Si bien, en nuestra opinión, este planteamiento resultaría cuestionable en determinados casos o siniestros concretos.

Por último, el artículo 14 de la LRMA cuyo título reza "Inexigiblidad de la obligación de sufragar los costes", determina que el operador no estará obligado a sufragar los costes imputables a las medidas de prevención, de evitación y de reparación de daños, en los siguientes supuestos: (1) Cuando demuestre que los daños o amenazas ambientales se debieron a: la actuación de un tercero ajeno a la organización, aunque se hubieran adoptado medidas de seguridad adecuadas. (2) Cuando el operador procediera conforme al cumplimiento de una orden o instrucción obligatoria dictada por una autoridad pública competente (incluyen la ejecución de un contrato público). Por último, se establece que (3) el operador no estará obligado a sufragar los costes de las medidas de reparación, cuando demuestre que no ha incurrido en culpa o negligencia y cuente con una autorización administrativa ambiental y se hubiera ajustado a la misma. Y, del mismo modo, en el caso de los denominados "riesgos del desarrollo" (Art. 14 apartados 1 y 2).

Así, en principio, conforme al régimen general que establece la Ley: el régimen de responsabilidad ambiental será aplicable a las actividades del Anexo III, aunque no existiera dolo, culpa o negligencia (Artículo 3.1 LRMA). No obstante, conviene apreciar las matizaciones que se observan en el tratamiento de las causas de exoneración del artículo 14.1 en relación con el apartado 2 del mismo artículo. El artículo 14.2 determina que "el operador no estará obligado a sufragar el coste imputable a las medidas reparadoras cuando demuestre que no ha incurrido en culpa, dolo o negligencia". De este modo, al operador le corresponderá las medidas adoptadas, las circunstancias y los datos precisos para alegar la aplicación de las excepciones que podrían aplicarse en su caso concreto.

En resumen, por lo que respecta a las causas que exoneran de responsabilidad, la LRMA ha preferido configurarlas en base a determinar las circunstancias que suponen excluir/exonerar de la obligación del pago de los gastos derivados de la ejecución de medidas preventivas, de eliminación, de evitación y de reparación de los daños producidos, según proceda en cada supuesto: En casos en los que el daño fuera producido por un tercero ajeno a la empresa y en los casos en que la actividad desarrollada efectivamente fuera conforme a la legalidad vigente, bajo el 
cumplimiento de una autorización administrativa o de órdenes dictadas por la autoridad competente.

En este punto, surgen varias cuestiones, entre otras: La posibilidad de plantear o reclamar -en los supuestos citados- una posible responsabilidad patrimonial de la Administración (conforme a la Ley 30/1992). Por otro lado, el planteamiento de una posible concurrencia de causas. En este último punto, la LRMA apunta como solución el estimar si efectivamente se han adoptado, en la práctica, las necesarias medidas preventivas y de seguridad en la instalación o con respecto a la actividad desarrollada.

En definitiva, la LRMA ha de interpretarse conforme a su propio espíritu, resaltando el enfoque preventivo y garante, su pretensión de reforzar la tutela ambiental. Por tanto, potenciando los deberes de precaución, prevención y diligencia debida.

En este sentido, el artículo 9.1 de la LRMA determina que "los operadores de las actividades económicas o profesionales están obligados a adoptar y a ejecutar las medidas de prevención, de evitación y de reparación de daños ambientales". Y, en su apartado 2, establece que los operadores de cualesquiera actividades están obligados a comunicar de forma inmediata a la autoridad competente la existencia de daños ambientales o de amenazas inminentes de dichos daños. Completando lo expresado, en la práctica, procederá observar si efectivamente el operador -aunque disponga de una autorización $\mathrm{u}$ otro acto habilitante- puede tener o hubiera podido tener conocimiento -con motivo de la actividad que desarrolla- de datos relevantes, circunstancias o aspectos que impliquen la concurrencia de un riesgo grave, un daño efectivo o una amenaza inminente. Pues, si así acontece, quedaría fundamentada la exigencia de responsabilidad al operador, en todo caso a efectos de afrontar la obligación de reparación (conforme al texto legal). El propio artículo 14.2.a) advierte que "Adicionalmente, será necesario que el operador se haya ajustado estrictamente en el desarrollo de la actividad a las determinaciones o condiciones establecidas al efecto en la referida autorización y a la normativa que le sea aplicable en el momento de producirse la emisión o el hecho causante del daño medioambiental".

El apartado 3 del artículo 14.3 determina que el operador estará obligado cuando concurran las circunstancias de los apartados 1 y 2 del art. 14- a adoptar las medidas de prevención, de evitación y de reparación de daños ambientales. Si bien, los costes podrá recuperarlos conforme al artículo 15. Los costes en que se haya incurrido se recuperarán:

1.1.) En los supuestos del art.14.1, ejerciendo acción de repetición frente a terceros o a la Administraciones públicas "a cuyo servicio se encuentre la autoridad pública que impartió la orden o la instrucción". 1.2.) En los supuestos del art. 14.2, la recuperación de costes procede en los términos establecidos por la normativa autonómica. Por tanto, con respecto a la recuperación de costes resultará preciso observar el desarrollo normativo aportado por las CC.AA. Por otro lado, se señala que lo mencionado resultará aplicable sin perjuicio de lo establecido en el artículo 34, en el caso de daños que afecten a bienes de Dominio público, sufragará los costes el Fondo Estatal de Reparación de Daños Medioambientales. 
Por tanto, considerando que las causas en materia de riesgo ambiental mantienen un alto componente científico, técnico e industrial, precisan necesariamente de conocimientos y medios especializados, requieren normas y conductas prudenciales, una especial cualificación profesional. Las cuales, en todo caso, sí son exigibles al operador que voluntariamente desarrolla una actividad empresarial en el mercado. Por tanto, en todo caso, el operador debe observar y comunicar una conducta responsable, diligente y apropiada, actuando conforme a Derecho.

\section{8.- Medidas preventivas, medidas de evitación y medidas de reparadoras de daños ambientales.}

El artículo 2 de la LRMA (Definiciones legales) especifica los conceptos de "medida preventiva o de prevención", "medida de evitación de nuevos daños", "medida reparadora o de reparación", así como el término "recuperación".

En los artículos 17y 19 de la LRMA se establecen las obligaciones del operador para adoptar medidas de prevención y de evitación de nuevos daños (art. 17) y, del mismo modo, se hace referencia a las medidas de reparación del daño producido (art. 19). De este modo, se determinan:

Las medidas preventivas: operan cuando se produzca una amenaza inminente de generar daños, el operador deberá adoptar, sin demora, las medidas preventivas necesarias y, si el daño se hubiera producido, deberá actuar del mismo modo para evitar nuevos daños. Así, el operador deberá comunicar de forma inmediata a la autoridad competente todos los datos con respecto a la amenaza o al daño producido.

Por su parte, la Administración podrá emitir resoluciones motivadas, podrá dar instrucciones o incluso podrá requerir en cualquier momento y exigir al operador la adopción de medidas preventivas. Del mismo modo, la propia Administración podrá adoptar las medidas necesarias, repercutiendo los costes al operador (conforme a los artículos 23 y 47 LRMA).

Las medidas de reparación: operan cuando se hubieran producido daños ambientales, en este caso, el operador informará sin demora a la autoridad competente sobre todos los aspectos de la situación producida y adoptará todas las medidas posibles para, de forma inmediata, restaurar los recursos y servicios dañados. Lo que implicará, a efectos prácticos, controlar, contener, y, siendo posible, eliminar los contaminantes o cualesquiera otros aspectos perjudiciales. Con objetivo de eliminar o impedir mayores o nuevos daños ambientales y efectos adversos para los recursos naturales, la salud humana o mayores daños en los servicios y, del mismo modo, las medidas reparadoras necesarias conforme a la decisión adoptada por la autoridad competente.

En la práctica, procede diferenciar tres subtipos: medidas de reparación primarias; medidas de reparación complementaria y medidas compensatorias.

En este punto, calibrar los posibles efectos derivados de una interpretación literal del artículo 19 en su apartado 2. En concreto, al referirse al operador de una actividad -no enumerada en el anexo III- que causara daños ambientales efectivos, se establece que sí está obligado a comunicarlo a la autoridad competente y, en 
consecuencia, deberá adoptar las medidas de evitación (exigencia que resulta razonable). Sin embargo, se indica que "sólo cuando medie dolo, culpa o negligencia" deberá adoptar las medidas reparadoras. Sin duda, la interpretación resulta clara.

Otra cuestión, en este punto, consiste en considerar su oportunidad por parte del operador. Por tanto, a modo de recomendación al operador, insistir en que en todo caso resultará conveniente diseñar-planificar y adoptar las medidas preventivas y correctoras necesarias para asegurar el desarrollo de la actividad eliminando o minimizando los riesgos. En concreto, observar dicha recomendación a efectos preventivos y a efectos probatorios; estimando su utilidad a efectos prácticos, en virtud de una posible necesidad probatoria que pudiera surgir posteriormente, demostrando de este modo la conducta apropiada y la diligencia debida del operador o profesional, sí así procede.

No obstante lo mencionado, la Ley advierte en el último párrafo del citado artículo 19.2 que "En todo caso, quedan obligados a la adopción de medidas de reparación los operadores que hubieran incumplido los deberes relativos a las medidas de prevención y de evitación de daños".

Por último, con respecto al ámbito temporal, la LRMA establece el criterio de la irretroactividad en el caso de daños causados antes del 30 de abril de 2007 (Disposición Transitoria única, 2). La irretroactividad de los daños causados con posterioridad al 30 de abril de 2007, si éstos proceden de una emisión, suceso o de una actividad concreta realizada y concluida antes de dicha fecha.

\section{y sostenible.}

9.-Conclusiones. Consideraciones para una estrategia empresarial responsable

Conforme se ha expuesto en este estudio, en la práctica, el nuevo régimen de responsabilidad ambiental instaurado por la LRMA española impone nuevas obligaciones a las empresas, en consecuencia conlleva un importante proceso de cambio en el seno de las organizaciones, en sus políticas y estrategias para adecuarlas al nuevo marco legal vigente en España, conforme al Derecho Europeo.

En este sentido, dicho proceso supone la implementación de sistemas propios de gestión integrada de la calidad ambiental y de gestión de riesgos, en todo vinculados directamente al propio modelo de responsabilidad corporativa adoptado por cada empresa u organización.

El marco legal vigente en España, conforme al europeo, en materia de responsabilidad ambiental advierte sobre los nuevos enfoques y planteamientos que deben ser afrontados de forma adecuada y preventiva por parte de las organizaciones en el ámbito de la responsabilidad empresarial por riesgos ambientales.

Si bien, todo ello ha de interpretarse como una oportunidad estratégica para generar valor empresarial y competitividad, estimando la calificación de "empresa responsable y sostenible". Así, desde esta perspectiva, debe asumirse la cultura positiva del riesgo empresarial.

En definitiva, la responsabilidad empresarial queda vinculada a la concreta aplicación de los medios y metodologías que prescribe el marco normativo vigente. Ahora bien, en todo caso y para todo tipo de empresas, conviene considerar el carácter 
preventivo y estratégico de los instrumentos facilitadores aplicables en el ámbito de la gestión medioambiental y de la gestión de riesgos (referidos en este trabajo). Instrumentos o herramientas que deben incorporarse de forma obligatoria o voluntaria, según los supuestos o modalidades deatribución dela responsabilidad, en los propios sistemas deresponsabilidad social corporativa. Por tanto, la utilidad de los mismos queda demostrada a todos los efectos, más allá de la fórmula legal empleada y del propio ámbito de aplicación de la LRMA. Por cuanto resultan relevantes para acreditar el grado de cumplimiento de los compromisos empresariales asumidos y comunicados a la toda la organización, a la sociedad y al propio mercado (principio de transparencia informativa), demostrando observar una conducta diligente, el cumpliendo de los requisitos legales, aportando las necesarias garantías -ya sean obligatorias o voluntariamente constituidas- .

Luego, más allá de sus consideraciones técnicas y jurídicas, en la actualidad y a futuro, la responsabilidad empresarial ambiental debe ser observada como una estrategia y oportunidad para generar valor; asegurando la reputación de la organización vinculada a un compromiso basado en un modelo de crecimiento sostenible.

\section{BIBLIOGRAFÍA:}

AA.VV.: "Gobernanza para el Desarrollo Sostenible", Cuadernos de Sostenibilidad y Patrimonio Natural, 7/2005, Fundación Santander Central Hispano.

ALMAGRO, Juan José: Aproximación a la Responsabilidad Social de la Empresa: reflexiones y propuesta de un modelo. Colección Cuadernos de la Fundación, $\mathrm{n}^{\circ} 132$, Fundación Mapfre, Madrid 2009.

ARANGÜENA PERNAS, A.: Auditoría medioambiental en la empresa, Madrid 1994.

ÁLVAREZ GARCÍA, V:: La normalización industrial, Valencia 1999.

BARUEL, J.: Cultura de empresa y Unión Europea: relaciones entre la cultura de las empresas y su competitividad en la UE. ESADE, Barcelona 2002.

CANTALAPIEDRA LÓPEZ, O.: "Seguros Ambientales", Derecho Ambiental, Revista Jurídica General, boletín del Il. Colegio de Abogados de Madrid, núm. 18, $3^{a}$ época, mayo 2001, pp. 35-72.

CAMPOS, Jorge. "La RSC en las pymes: ¿nueva sensibilización social o necesaria estrategia comercial?.", en Estrategia Financiera: Revista para la Dirección Financiera y Administrativa, núm. 257 - enero 2009.

CARRILLO DONAIRE, J.A.: El Derecho de la seguridad y de la calidad industrial, Madrid 2000.

DE LAS HERAS, J.L.: "Aseguramiento de la Responsabilidad Civil por Contaminación en España". Gerencia de Riesgos n ${ }^{\circ}$ 50, $2^{\circ}$ trimestre,1995.

DE MIGUEL, C.: La Responsabilidad Civil por Daños al Medio Ambiente. Ed. Civitas, Madrid 1997, p. 85-86.

DOPAZO FRAGUÍO, Pilar: "La gestión integral de riesgos en el entorno de la PYME 
actual (riesgos operativos y tipología)", en Jornada Fundación Mapfre "La Cultura de la gerencia de riesgos en la Pyme", Madrid 1/12/2009.

DOPAZO, Pilar: "Calidad, Innovación y Sostenibilidad: retos y aportaciones para generar valor y competencia empresarial", en Monográfico Propiedad Industrial y Nuevas Tecnologías, Revista de la Contratación Electrónica, RCE nº 99 / diciembre 2008. Págs. 169 a 193. ISSN-1576-2033.

DOPAZO FRAGUÍO, P: El régimen jurídico de las marcas de calidad ambiental: Etiqueta ecológica y tutela ambiental. Ed. EXILIBRIS Ediciones, Madrid 2001.

DOPAZO, P:"Las Nuevas Marcas de Garantía de la Calidad. Aspectos Jurídicos y Supuestos Prácticos", Ponencia en Jornada de Promoción de la Propiedad Industrial y las Nuevas Tecnologías, Uc3m, Madrid, 11 de diciembre de 2008.

DOPAZO, P.: "Calidad y Excelencia Empresarial a través del Diseño Industrial: Ecodiseño y Ecoetiqueta", Congreso Internacional: El Diseño Industrial como Clave de la Competitividad Empresarial. (Uc3m, DDI y OEPM.), celebrado en Madrid el 3 y 4 de diciembre de 2008, en Actas del Congreso Internacional: Diseño Industrial como Clave de la Competitividad Empresarial. (AA.VV.), publicadas en soporte digital-CD, ISBN 978-84-691-6922-3.

ESCORIAL BONET, Ángel. "Ve la luz la nueva ISO 31000 sobre gerencia de riesgos", en Aseguranza, $\mathrm{n}^{\circ} 145$, diciembre 2009, p. 18.

ESCORIAL BONET, Ángel."Análisis técnico de riesgos ambientales" (comunicación Riskia, S.A.) en Jornada Responsabilidad Medioambiental, Zaragoza 15-abril-2008.

ESTEVE PARDO, J.: Técnica, riesgo y Derecho, Barcelona 1999.

ESTEVE PARDO, José: Ley de Responsabilidad Medioambiental. Comentario sistemático. Ed. Marcial Pons, Madrid 2008.

FUNDACIÓN MAPFRE, Instituto de Ciencias del Seguro: Foro de Responsabilidad Civil Medioambiental, El Plantío, Madrid, 1-junio-2006.

JUST ESCRIVÁ, J.J.: "Estudios sobre la Responsabilidad Civil Medioambiental y su Aseguramiento. La Obligatoriedad de Aseguramiento de la Responsabilidad Civil por Daños al Medio Ambiente". Ed. Española de Seguros, S.L., Madrid, 1997. p.275.

MARTÍN MATEO, R.: Nuevos instrumentos para la tutela ambiental, Trivium, Madrid 1994.

MARTÍN MATEO, R.: El marco público de la economía de mercado, Madrid 1999.

NOGUEIRA LÓPEZ, ALBA: "Fomento Público de la Responsabilidad Social Corporativa: Contratación Pública y Sistemas de Gestión Ambiental". En AA.VV. (Elena F. Pémrez Carillo, Coord.): Gobierno corporativo y responsabilidad social de las

NOGEUIRA LÓPEZ, A.: Auditorías ambientales, intervención pública ambiental y autocontrol empresarial, Marcial Pons, Madrid 2000. 
NOGUERIA LÓPEZ, A.: "La reforma del Reglamento comunitario de ecogestión y ecoauditorías", Revista Aranzadi de Derecho Ambiental, 2002, pp. 225-236.

OCDE (Organización para la Cooperación y el Desarrollo Económico). "Aspectos políticos de los seguros. Seguros y riesgos ambientales. Un análisis comparativo del papel de los seguros en la gestión de los riesgos relacionados con el medio ambiente", Ministerio de Medio ambiente, MMA, Madrid 2007.

ORTÍZ GARCÍA, Mercedes: "Gobemanza y sostenibilidad", R. Revista de Estudios de la Administración Local, núm. 289/2002, pp.91-139.

PAVELEK, E.: Estudios sobre responsabilidad civil medioambiental y su aseguramiento. La cobertura del riesgo medioambiental en las pólizas de responsabilidad civil general. Ed. Española de Seguros, S.L., Madrid 1997, pp. 202-205

PAVELEK, Eduardo: "La Asegurabilidad de los Riesgos Medioambientales", Gerencia de Riesgos $\mathrm{n}^{\circ} 46,2^{\circ}$ trimestre,1994.

PAVELEK, E.: "El Pool Español de Riesgos Medioambientales", 1994.

PAVELEK, E.: "Seguro y Riesgos Medioambientales", Revista Española de Seguro, nº 64/1990.

PAVELEK, E.: "Los Seguros Medioambientales. Estudio Comparado". Gerencia de Riesgos n $\mathrm{n}^{\circ}$ 48/1994.

PAVELEK, E.: "Garantías financieras obligatorias" (conferencia) en Jornada sobre la Nueva Ley de Responsabilidad Medioambiental. Implicaciones para las empresas. Gómez-Acebo \& Pombo, Abogados, Madrid, 18-enero-2008.

PÉREZ CARRILLO, Elena F. (coord.- AA.VV.): Gobierno corporativo y responsabilidad social de las empresas. Marcial Pons, Madrid 2009.

POZO FERNÁNDEZ, Raúl del. "El valor de la responsabilidad social corporativa en un entorno de crisis.", en Estrategia Financiera: Revista para la Dirección Financiera y Administrativa, núm. 257, enero 2009, pp.30-33.

SALAS FUMÁS, V.: "¿Sustituye la responsabilidad social al buen gobierno de la empresa?", en el núm. monográfico titulado "Empresa Sostenible", Economistas 106/2005, Colegio de Economistas de Madrid, pp. 4-11.

SALAS FUMÁS, V.: El gobierno de la empresa. Fundación La Caixa, Barcelona 2002. SÁNCHEZ MORÓN, M.: Derecho Administrativo. Parte general. Ed. Tecnos, Madrid 2008, pp. 659-661.

SIERRA GIL DE LA CUESTA, I. (dtor.). "La responsabilidad civil medioambiental", en Estudio de Derecho Judicial, 80-2005, Junta de Andalucía / CGPJ, Consejo General del Poder Judicial, Centro de Documentación Judicial, Madrid 2006.

TEJERA OLIVER, J.L.: "I+D+i, sostenibilidad y competitividad: III.- La responsabilidad social y su normalización", IEE nº 4/2009. 